\title{
Intrahepatic cholangiocarcinoma with clear cell type following laparoscopic curative surgery
}

\author{
Takuya Yamamoto ${ }^{1}$, Tomoyuki Abe ${ }^{2 *}$, Akihiko Oshita ${ }^{2,4}$, Shuji Yonehara ${ }^{3}$, Yoshio Katamura', \\ Nozomu Matsumoto ${ }^{1}$, Tsuyoshi Kobayashi ${ }^{4}$, Masahiro Nakahara' ${ }^{2}$, Hideki Ohdan ${ }^{4}$ and Toshio Noriyuki ${ }^{2,4}$
}

\begin{abstract}
Background: Intrahepatic cholangiocarcinoma (ICC) is the second most common malignancy of primary liver cancer. Among the several pathological types of ICC, only five cases of the clear cell type have been reported, including the one presented below. Here we report a unique case of clear cell type ICC following laparoscopic hepatectomy.

Case presentation: A 67-year-old woman had a history of hepatitis B virus. Computed tomography revealed a ringlike enhanced mass $35 \mathrm{~mm}$ in diameter at segment 7 in the early phase. The enhancement was prolonged to the late phase through the portal phase, while the shape was irregular. Ethoxybenzy magnetic resonance imaging revealed that the tumor had a low signal intensity on T1-weighted imaging and a high signal intensity on T2-weighted imaging. Diffusion-weighted images identified that the tumor had remarkably high signal intensity. Tumor enhancement was not detected throughout the tumor in the hepatocyte phase. Upon ICC diagnosis, a laparoscopic S7 subsegmentectomy was performed. The patient's postoperative course was uneventful. An immunohistochemical examination revealed that the cells tested positive for cytokeratin 7 (CK7), CK19, and CD56 and negative for CK20, CD10, a-fetoprotein, thyroid transcription factor-1. At 2 years after surgery, the patient remains alive without recurrence.
\end{abstract}

Conclusions: Here we presented a case of clear cell ICC that was treated by laparoscopic hepatectomy. Immunological analysis, especially by CD56 and several CK markers, is helpful for diagnosing this disease.

Keywords: Clear cell type, Intrahepatic cholangiocarcinoma, Laparoscopic hepatectomy

\section{Background}

Intrahepatic cholangiocarcinoma (ICC) is the second most common malignancy of primary liver cancer and has a dismal prognosis. Previous reports demonstrated a 5 -year overall survival rate of around $40 \%$ even after curative surgery $[1,2]$. The establishment of a systemic perioperative chemotherapy regimen is currently underway. Recently, the efficacy of neoadjuvant chemotherapy for locally advanced ICC was reported [3]. ICC has several types, including clear cell. Cases of clear cell ICC are limited, as only five have been reported including the one presented here; thus, its imaging characteristics and

\footnotetext{
*Correspondence: t.abe.hiroshima@gmail.com

${ }^{2}$ Department of Surgery, Onomichi General Hospital, 1-10-23, Hirahara, Onomichi, Hiroshima 722-8508, Japan

Full list of author information is available at the end of the article
}

prognosis remain unclear. Here we report a case of clear cell ICC following laparoscopic hepatectomy.

\section{Case presentation}

A 67-year-old woman was admitted to our hospital with the chief complaint of high fever. She had a past medical history of hepatitis B virus. Laboratory data showed Child-Pugh liver disease grade A and liver damage grade A. Levels of tumor makers such as carcinoembryonic antigen, carbohydrate antigen 19-9, $\alpha$-fetoprotein (AFP), and protein induced by vitamin $\mathrm{K}$ absence or antagonist-II were within the normal ranges. Dynamic abdominal computed tomography represented a ring-like enhanced mass $35 \mathrm{~mm}$ in diameter at segment 7 at the early phase (Fig. 1a). The enhancement was prolonged to the late phase through the portal phase, while the shape was irregular (Fig. 1b, c). Dynamic magnetic resonance 

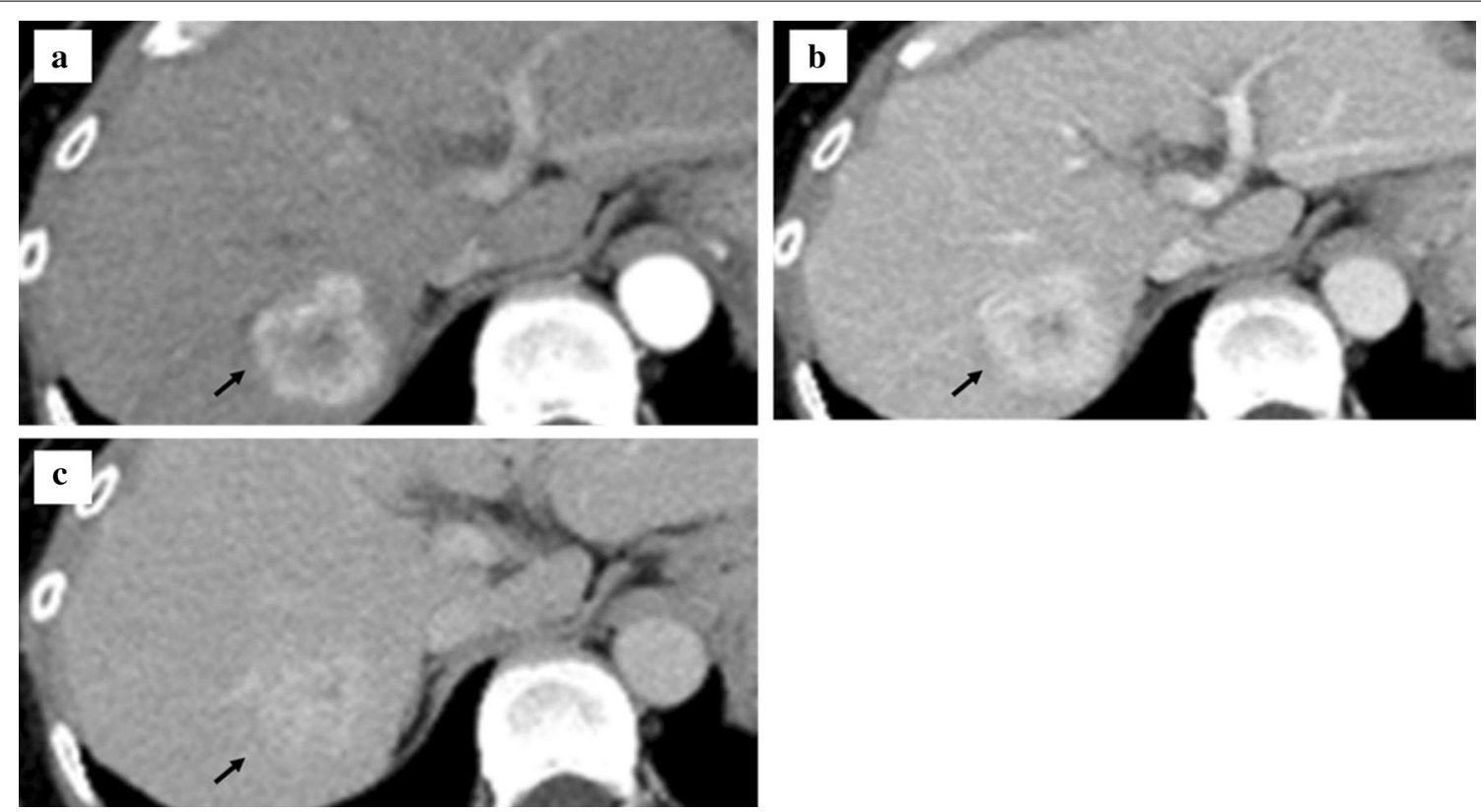

Fig. 1 Findings of dynamic abdominal computed tomography. a The arterial phase showing a ring-like enhanced mass at segment 7 measuring $35 \mathrm{~mm}$ in diameter shaped like an irregular arrow. b Portal phase. c The enhancement was prolonged to the late phase

imaging revealed that the tumor had a low signal intensity upon T1 weighting (Fig. 2a) and a high signal intensity upon T2 weighting (Fig. 2b). Diffusion-weighted images identified that the tumor had remarkably high signal intensity. The tumors have ring-like enhancement at the early phase (Fig. 2c) that was not detected throughout the tumor at the hepatocyte phase (Fig. 2d). Radiological findings suggested that the tumor was ICC or combined hepatocellular carcinoma (HCC)-cholangiocellular carcinoma for which a laparoscopic S7 subsegmentectomy was performed. On operative finding, the surface of the liver was slightly irregular due to the hepatitis B viral infection. Under intraoperative ultrasonography guidance, the tumor was closed to the right hepatic vein without direct invasion and a laparoscopic S7 subsegmentectomy was completed. The operative time was $528 \mathrm{~min}$, and the intraoperative blood loss was $500 \mathrm{~mL}$. On macroscopic examination, the tumor was solid and whitish with irregular margins (Fig. 3a). The tumor was $35 \times 32 \times 30 \mathrm{~mm}$ in dimension. Microscopically, most of the tumor cells had an enlarged nucleus-cytoplasmic ratio, and they proliferated into funicular or small alveolar structures with stromal tissue consisted of hyaline collagen fiber. The differentiation was poor adenocarcinoma with abundant clear cytoplasm (Fig. 4a, b). An immunohistochemical examination revealed that the cells tested positive for cytokeratin 7 (CK7), CK19, and CD56 (Fig. 4c-i) but negative for CK20, CD10, AFP, and thyroid transcription factor-1 (Fig. $4 \mathrm{f}-\mathrm{i}$ ). Based on these findings, the tumor was diagnosed as a clear cell ICC, T1aN0M0, stage IA according to the American Joint Committee on Cancer/Union for International Cancer Control staging classification $8^{\text {th }}$ edition.

On the 7th postoperative day, she was discharged without complications. Although no adjuvant chemotherapy was administered, her postoperative course was uneventful without a recurrence at 2 year after surgery.

\section{Conclusions}

Histopathologically, ICC develops as various tissues form, such as well-differentiated adenocarcinoma, adenosquamous carcinoma, mucinous carcinoma, mucoepidermoid carcinoma, squamous carcinoma, sarcomatoid carcinoma, and signet-ring cell carcinoma [4, 6]. Among them, the clear cell type is particularly rare. Due to its rarity, its prognosis and radiological findings remain unclear. Nevertheless, radiological characteristic might be sustained intra-tumor staining in the late phases of dynamic CT. Clear cell carcinoma is generally thought to be derived from the ovary and kidney. Some cancers show a clear cell type, such as ICC, HCC, gallbladder carcinoma, and metastasis of lung or thyroid cancer [4, 6-8]. The incidence of clear cell gallbladder carcinoma is reportedly around $1 \%$ [7].

Immunohistochemical analysis would play an important role in distinguishing between clear cell $\mathrm{HCC}$ and other types. Positivity for CK7 and the absence of CK20 staining are considered features of cholangiocarcinoma 

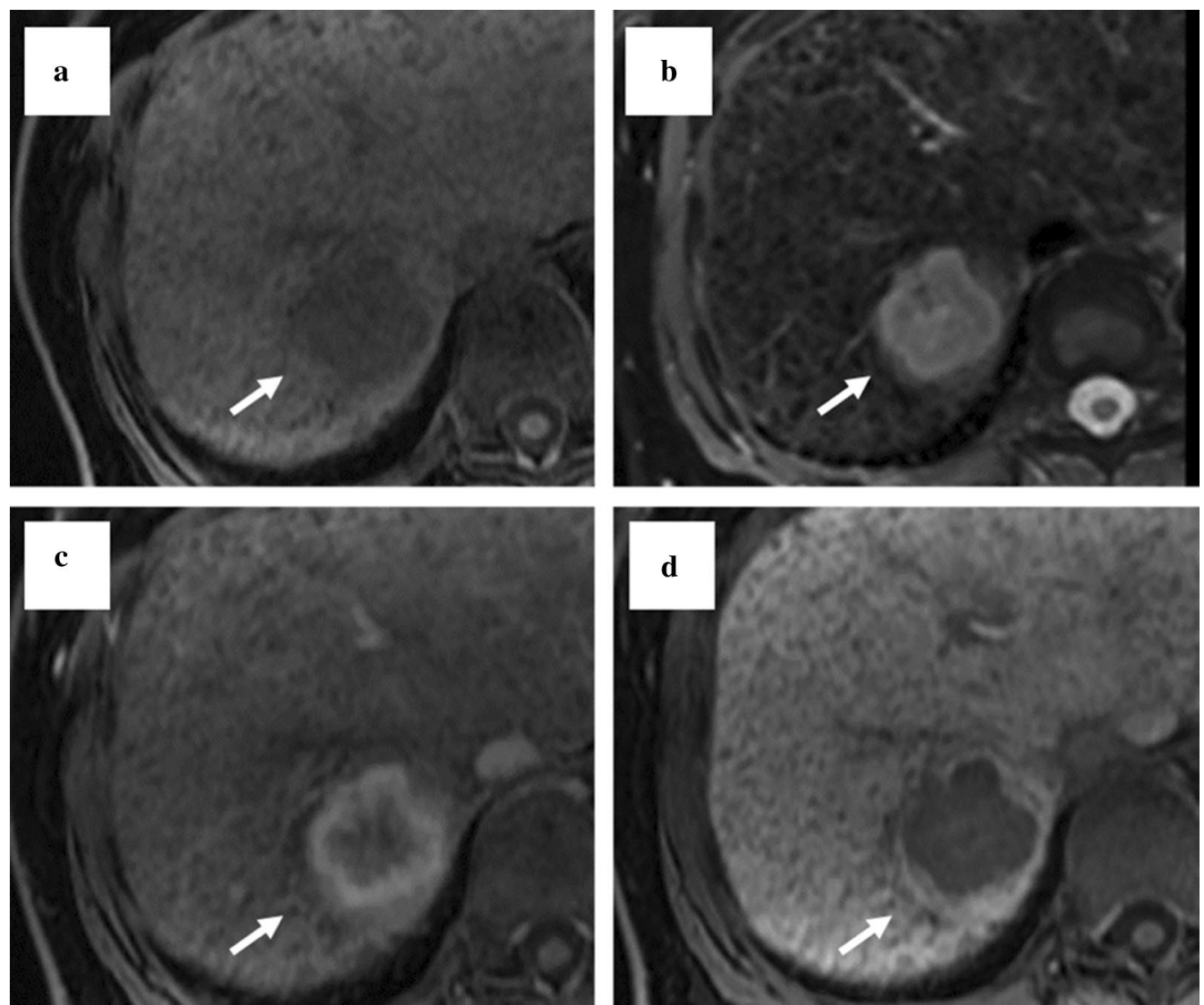

Fig. 2 Findings of magnetic resonance imaging (MRI). a The tumor shows a low signal intensity on a T1-weighted image. b The tumor shows a high signal intensity on a T2-weighted image. c At the early phase on ethoxybenzyl magnetic resonance imaging (EOB-MRI), the tumor shows ring-like enhancement. $\mathbf{d}$ The enhancement is not detected throughout the tumor in the hepatocyte phase on EOB-MRI
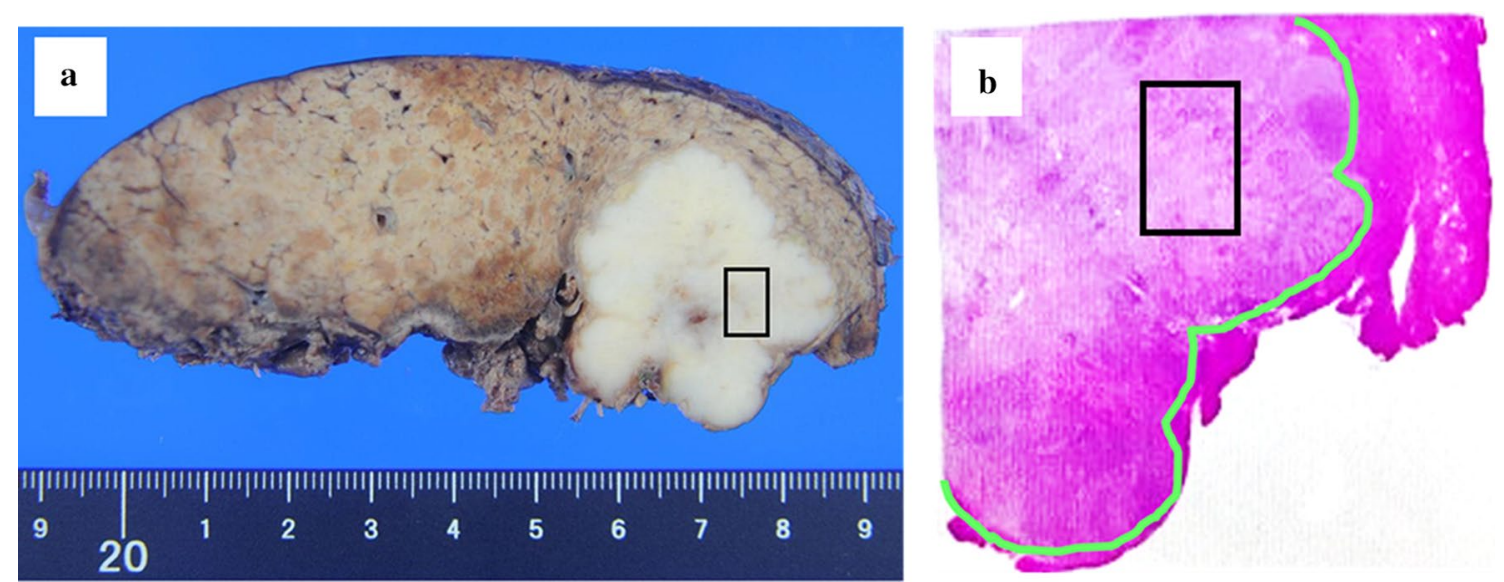

Fig. 3 Imaging. a Gross appearance of the cut surface showing a solid whitish mass measuring $35 \mathrm{~mm} \times 32 \mathrm{~mm} \times 30 \mathrm{~mm}$ with irregular margins. In the area surrounded by the black line on $\mathbf{a}$ and $\mathbf{b}$, clear cells are abundantly clear 

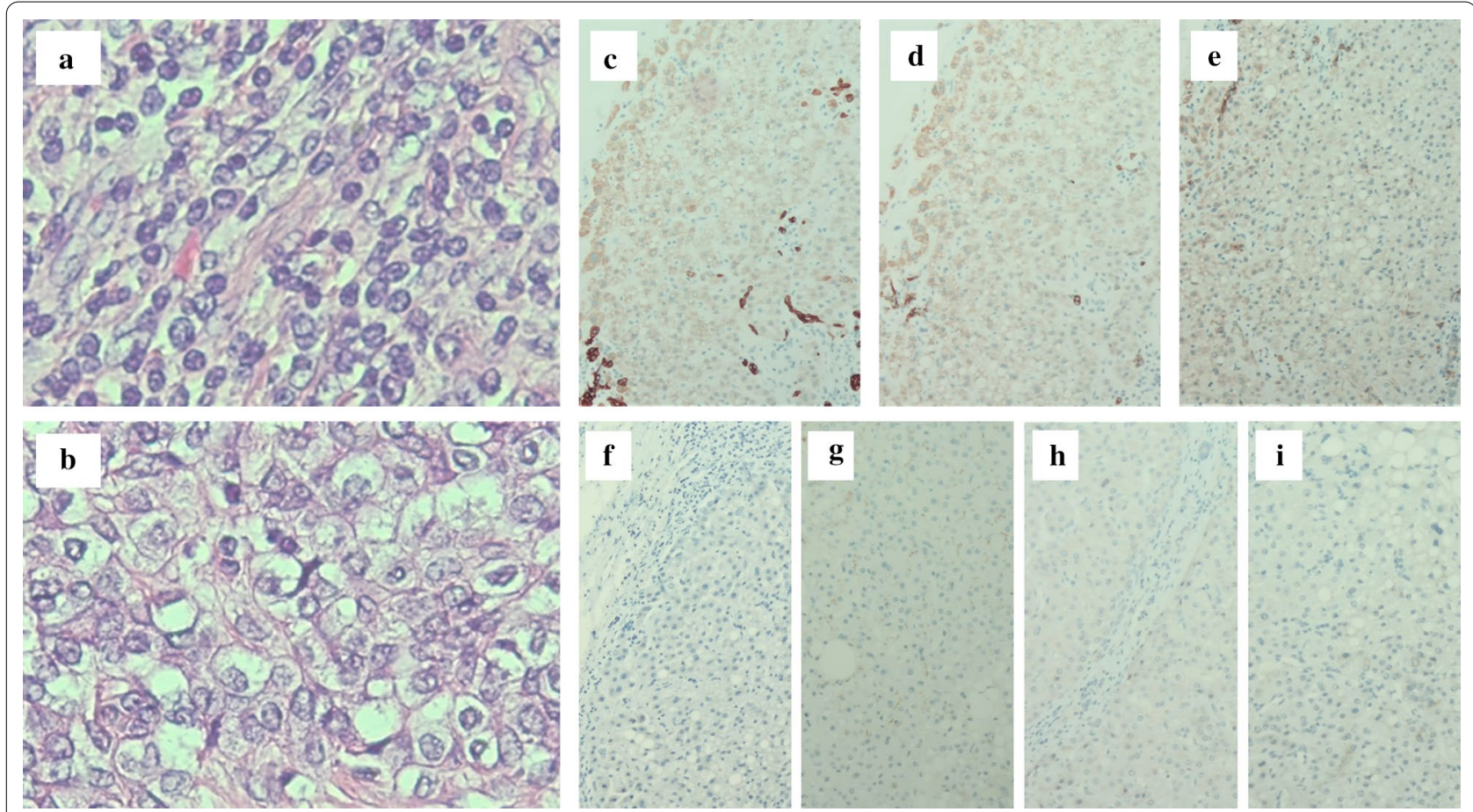

Fig. 4 Histopathological findings. $\mathbf{a}$, b The tumor consists of poorly differentiated adenocarcinoma tissue (a) and clear cells with atypical nuclei (b) (hematoxylin and eosin stain); c CK7 expression is positive; $\mathbf{d}$ CK19 expression is positive; e CD56 expression is positive; $\mathbf{f}$ CK20 expression is negative; $\mathbf{g}$ CD10 expression is negative; $\mathbf{h}$ a-fetoprotein expression is negative; $\mathbf{i}$ thyroid transcription factor-1 expression is negative

$[4,5]$. It has been reported that CD56 positivity relates to the clear cell change $[3,9]$, while ICC shows negativity for vimentin and CD56 [3, 10]. Glycogen, mucin, and lipids also cause the clear cell change [7,11, 12]; in this case, glycogen reactivity was shown (Fig. 4). We could distinguish clear cell ICC from clear cell HCC in terms of differences in the reactivities of HepPar-l, AFP, and Hepatocyto [4, 9, 11-14]. Renal cell carcinoma is also a well-known clear cell tumor, and its immunohistochemical features include negativity for vimentin, CD10, and S-100 protein $[4,8-11,15]$.

Table 1 shows the cases of clear cell type ICC reported to date. Curative surgery was performed in most cases. Among them, three patients survived without recurrence after receiving curative surgery. Based on this observation, clear cell ICC might have a better prognosis than ordinary ICC. Therefore, aggressive surgical resection of this disease is recommended. To the best of our knowledge, this is the first report of a clear cell ICC case undergoing laparoscopic hepatectomy. Laparoscopic hepatectomy is increasingly used to treat primary liver tumors with reportedly fewer postoperative complications. Ban et al. proposed that degree of difficulty of laparoscopic hepatectomy is related to the maximal tumor diameter, tumor location, and liver function. In this case, regardless of a relatively high difficulty score, laparoscopic hepatectomy was achieved [16]. In the present case, no adjuvant chemotherapy was administered and the patient's postoperative course was uneventful without recurrence for 12 months. Clear cell ICC is a rare

Table 1 Reported cases of clear cell type intrahepatic cholangiocarcinoma

\begin{tabular}{|c|c|c|c|c|c|c|c|}
\hline Author & Year & Age/sex & Size $(\mathrm{cm})$ & Treatment & Adjuvant chemotherapy & Immunohistochemical analysis & Prognosis \\
\hline Tihan T, et al. & 1998 & $72 / \mathrm{M}$ & 15 & Surgery & Not described & $\mathrm{N} / \mathrm{A}$ & Alive at 30 m \\
\hline Logani S, et al. & 1998 & $64 / F$ & 12 & Surgery & Not described & $\mathrm{N} / \mathrm{A}$ & Not described \\
\hline Falta EM, et al. & 1999 & $50 / \mathrm{M}$ & 1.5 & Surgery & Not described & $\mathrm{N} / \mathrm{A}$ & Not described \\
\hline Fernandes SR, et al. & 2017 & $51 / F$ & 9.5 & Surgery & + & $\mathrm{CK} 7(+), \mathrm{CK} 20(-)$ & Alive at $2 \mathrm{yr}$ \\
\hline Our case & 2020 & $67 / F$ & 3.5 & Surgery & - & CK7(+), CK19, CD56(-), CK20, CD10, TTF1 & Alive at $2 \mathrm{yr}$ \\
\hline
\end{tabular}


malignancy with no effective perioperative chemotherapy; therefore, careful follow-up is necessary to improve postoperative prognosis.

In conclusion, here we presented a case of clear cell ICC following laparoscopic hepatectomy. Immunological analysis, especially by CD56 and several CK markers, is helpful for diagnosing this disease.

\section{Abbreviations}

AFP: a-Fetoprotein; CK: Cytokeratin; EOB-MRI: Ethoxybenzyl magnetic resonance imaging; HCC: Hepatocellular carcinoma; ICC: Intrahepatic cholangiocarcinoma; MRI: Magnetic resonance imaging; PAS: Periodic acid-Schiff.

\section{Acknowledgements}

Not applicable.

\section{Authors' contributions}

TA and TY conceived the presented idea and developed the theory and performed the computations. TM, TY, AO, TK, SY, MN, HO and TN encouraged to investigate a specific aspect and supervised the findings of this work. All authors discussed the results and contributed to the final manuscript. All authors read and approved the final manuscript.

\section{Funding}

There is none of the funding body in the design of the study and collection, analysis, and interpretation of data and in writing the manuscript.

\section{Availability of data and materials}

Data sharing not applicable to this article as no datasets were generated or analyzed during the current study.

\section{Ethics approval and consent to participate}

All procedures used in this research were approved by the Ethical Committee of our institution.

\section{Consent for publication}

Written informed consent was obtained from the patient for publication of this case report and accompanying images.

\section{Competing interests}

The authors declare that they have no competing interests.

\section{Author details}

${ }^{1}$ Department of Gastroenterology, Onomichi General Hospital, Onomichi, Hiroshima, Japan. ${ }^{2}$ Department of Surgery, Onomichi General Hospital, 1-10-23, Hirahara, Onomichi, Hiroshima 722-8508, Japan. ${ }^{3}$ Department of Pathology, Onomichi General Hospital, Onomichi, Hiroshima, Japan.

${ }^{4}$ Department of Gastroenterological and Transplant Surgery, Graduate School of Biomedical and Health Sciences, Hiroshima University, Hiroshima, Japan.

Received: 26 August 2020 Accepted: 29 September 2020

Published online: 07 October 2020

\section{References}

1. Ercolani G, Vetrone G, Grazi G, Gian L, Aramaki O, Cescon M, et al. Intrahepatic cholangiocarcinoma: primary liver resection and aggressive multimodal treatment of recurrence significantly prolong survival. Ann Surg. 2010;252:107-14

2. Abe T, Amano H, Shimamoto F, Hattori M, Kuroda S, Kobayashi T, et al. Prognostic evaluation of mucin-5AC expression in intrahepatic cholangiocarcinoma, mass-forming type, following hepatectomy. Eur J Surg Oncol. 2015:41:1515-21.

3. Le Roy B, Gelli M, Pittau G, Allard MA, Pereira B, Serji B, et al. Neoadjuvant chemotherapy for initially unresectable intrahepatic cholangiocarcinoma. Br J Surg. 2018;105:839-47.

4. Toriyama E, Nanashima A, Hayashi H, Abe K, Kinoshita N, Yuge S, et al. A case of intrahepatic clear cell cholangiocarcinoma. World J Gastroenterol. 2010;16:2571-6.

5. Fernandes SR, Baldaia C, Marques HP, Tortosa F, Ramalho F. Intrahepatic clear cell cholangiocarcinoma - an uncommon histologic subtype: case report and literature review. Rev Esp Enferm Dig. 2017;109:382-5.

6. Buettner S, van Vugt JLA, Izermans JN, Koerkamp B. Intrahepatic cholangiocarcinoma: current perspectives. Onco Targets Ther. 2017:10:1131-42.

7. Vardaman C, Albores-Saavedra J. Clear cell carcinoma of gallbladder and extrahepatic bile ducts. Am J Surg Pathol. 1995;19:91-9.

8. Miyazawa M, Torii T, Toshimitsu Y, Kamizasa N, Suzuki T, Shinozuka N, et al. a-Fetoprotein-producing clear cell carcinoma of the extrahepatic bile ducts. J Clin Gastroenterol. 2006:40:555-7.

9. Haas S, Gütgemann I, Wolff M, Fischer HP. Intrahepatic clear cell cholangiocarcinoma: immunohistochemical aspects in a very rare type of cholangiocarcinoma. Am J Surg Pathol. 2007;31:902-6.

10. Nakanuma Y, Sasaki M, Ikeda H, Sato Y, Zen Y, Kosaka K, et al. Pathology of peripheral intrahepatic cholangiocarcinoma with reference to tumorigenesis. Hepatol Res. 2008;38:325-34

11. Tihan T, Blumgart L, Klimstra DS. Clear cell papillary carcinoma of the liver: an unusual variant of peripheral cholangiocarcinoma. Hum Pathol. 1998;29:196-200

12. Albores-Saavedra J, Hoang MP, Murakata LA, Sinkre P, Yaziji H. Atypical bile duct adenoma, clear cell type: a previously undescribed tumor of the liver. Am J Surg Pathol. 2001;25:956-60.

13. Falta EM, Rubin AD, Harris JA. Peripheral clear cell cholangiocarcinoma: a rare histologic variant. Am Surg. 1999;65:592-5.

14. Adamek HE, Spiethoff A, Kaufmann V, Jakobs R, Riemann JF. Primary clear cell carcinoma of noncirrhotic liver: immunohistochemical discrimination of hepatocellular and cholangiocellular origin. Dig Dis Sci. 1998;43:33-8.

15. Logani S, Adsay V. Clear cell cholangiocarcinoma of the liver is a morphologically distinctive entity. Hum Pathol. 1998;29:1548-9.

16. Ban D, Tanabe M, Ito H, Otsuka Y, Nitta H, Abe Y, et al. A novel difficulty scoring system for laparoscopic liver resection. J Hepatobiliary Pancreat Sci. 2014;21:745-53.

\section{Publisher's Note}

Springer Nature remains neutral with regard to jurisdictional claims in published maps and institutional affiliations.

\section{Submit your manuscript to a SpringerOpen ${ }^{\circ}$ journal and benefit from:}

- Convenient online submission

- Rigorous peer review

- Open access: articles freely available online

- High visibility within the field

- Retaining the copyright to your article

Submit your next manuscript at springeropen.com 